\title{
Factors Affecting Knowledge Transfer in Public Organization Employees
}

\author{
Md. Zahidul Islam ${ }^{1}$, Ikramul Hasan ${ }^{1} \&$ Mohammad Habibur Rahman ${ }^{2}$ \\ ${ }^{1}$ School of Business and Economics, Universiti Brunei Darussalam, Bandar Seri Begawan, Brunei \\ ${ }^{2}$ Mohammed Bin Rashid School of Government, Dubai, UAE \\ Correspondence: Md. Zahidul Islam, UBD School of Business and Economics, Universiti Brunei Darussalam, \\ Jalan Tungku Link, Gadong, BE-1410, Bandar Seri Begawan, Brunei. E-mail: zahidul.islam@ubd.edu.bn
}

Received: October 13, 2014 Accepted: December 18, 2014 Online Published: January 14, 2015

doi:10.5539/ass.v11n4p223 URL: http://dx.doi.org/10.5539/ass.v11n4p223

\begin{abstract}
Managing knowledge is considered an essential resource for both public and private sector organizations. Effective transfer of knowledge (KT) among the employees could give a better platform in public entities to serve its clients in a more innovative and efficient way. In the context of Southeast Asia, studies on KT in public offices in Brunei compared to that in Singapore and Malaysia is relatively low. This study has made an attempt to investigation the relationship between cultural elements (trust, communication between employees, rewards and learning \& development) and Knowledge Transfer with organizational socialization as a moderating variable. A structured questionnaire survey was conducted to collect responses from a range of public sector employees. In results the findings reveal that there is a significant relationship between learning \& development and KT, but the hypotheses related to the other three variables: trust, communication and reward remain insignificant. On the other hand with the moderating effect trust shows significant influence over KT in building relationship with help of socialization.
\end{abstract}

Keywords: knowledge transfer, cultural elements, organizational socialization, public organization

\section{Introduction}

Knowledge is considered one of the key resources in many organizations (Jasimuddin, 2012). The creation, transformation, and utilization of knowledge are seen as an important concern for management research and practice in the 21st century (Hasan, Low, \& Islam, 2013). Since the operating core of organizations consist to a great extent of specialists and their expert knowledge, there is growing demand from management research to determine the key elements of knowledge management (KM) and their interactions (Handzic, 2011; M. Wilkesmann \& U. Wilkesmann, 2011). In addition, Grant (1996) and Conner and Prahalad (1996) also argued in their study that knowledge management has significant influence over strategy formulation and implementation. Davenport et al. (1998) also comply with this fact that in a modern economic society, organizational competitiveness heavily relies on its ability to leverage and manage knowledge. Moreover, organizations are not able to create knowledge themselves since knowledge is created by individuals, leveraging knowledge is only doable when individuals are ready to share their knowledge with others (Zhang \& Ng, 2012). Constructing this wisdom also necessitates the repetitive creation of new knowledge, and the transfer and interpreting of this new knowledge within the existing knowledge contexts of other parts of the organization (Kusunoki et al., 1998). Overviewing all these perspectives, therefore, a challenge may arise for the contemporary organizations as to how to encourage their employees to share their knowledge with others within teams and cross organizational units (Choi et al., 2008). According to Ives et al. (2003), the effectiveness of organizational knowledge transfer (KT) is influenced by key organizational factors such as structure, culture, processes, strategy and information technology. Therefore, knowledge can be enumerated as an important resource for organizations and the effective transfer of knowledge between employees could be a striking factor for public organizations to improve their services to citizens. Hence, the aim of this research is to propose a conceptual framework to examine the relationships between cultural elements (trust, communication between staff, reward, learning \& development), organizational socialization and KT among the public sector employees in Brunei.

Public sector organizations have to excel over the long run and use creativity and innovation to add value for quality services to the people of the country concerned. In public service context, the term 'quality' is more 
widely perceived by Bovaird and Loffler, who think that quality ranges from 'fitness for purpose' (i.e. meeting organizational objectives') to 'meeting customer expectations' (i.e. deriving service excellence from customer psychology) and even to the extent of 'passionate emotional involvement' (i.e. going beyond language and number) In their conceptual construct on public service quality, Bovaird and Loffler go beyond quality of public services to the ultimate value of 'quality of life' (Bovaird \& Loffler, 2009). Excellence in public service is therefore facilitated by a journey towards understanding the needs and expectations of people. Knowledge transfer as an effective instrument in that journey can equip public servants with adequate insights and information in an interconnected manner.

Malaysia and Singapore are considered to be the two leading states in championing knowledge management and KT practices in Southeast Asia. Malaysia's knowledge-based economy was strategically aligned with its vision 2020. To make this alignment work, the Malaysian Administrative Modernization and Planning Unit gives effort to implement knowledge management initiatives in the public sector to enable the government to manage and share knowledge possessed by various government agencies (Noorazah et al., 2011). Singapore managed to have leveraged its knowledge successfully. With a population of about five million people it is one of the smallest, yet one of the leading innovative economies in the World and became a model for many countries including Brunei.

Located in the Borneo Island in Southeast Asia, Brunei Darussalam is a small Sultanate and its government is a combination of Weberian bureaucracy and a traditional monarchic system Since its independence in 1984, the government of Brunei has made economic diversification as its prime economic agenda to decrease its heavy dependence on oil and gas industry (Farhana, 2013) and that agenda has been boldly incorporated in the country's long term policy vision or commonly known as Wawasan 2035 (Vision 2035) (Government of Brunei, 2014). With its 44,800 employees in 13 Ministries, Brunei has a good size of civil service serving its 400,000 citizens. In the absence of a vibrant private sector, the significance of public sector is felt everywhere. In his New Year 2014 Titah (speech), even the Sultan of Brunei inspires the civil servants to cater to the needs of the private businesses: “...public service is the government's engine in providing quality service to not just the public but also the business community (Bulletin, 2014). Of late, the country has engaged and produced good policies in education (e.g. SPN21), health (e.g. anti-smoking campaign and improved data-based patient information system Bru-HIMS), environment (e.g. zero-burning, plastic bag control) and so on. On the economic front, it has introduced innovative program on Islamic banking \& finance, halal food and tourism, creative arts, food production and so forth. Facilitated by an emerging consultative culture, there is now an increased appetite for new knowledge, innovative ideas, good thoughts and good policies in the Bruneian society at large. The ministries and departments are visibly more focused than any time in the past to benchmark their services, to achieve their strategic goals and also to align their collective efforts to take the country forward to achieve its vision-Wawasan 2035. However, often times, the knowledge gained from these innovative thoughts, dialogues, discussions, policy discourses are not documented, shared and transferred within and between entities. Also, not much empirical research has been conducted on KT practices in the public sector domain. Therefore, this empirical research, with its modest sample size, attempts to make a breakthrough in getting an overview of the KT dynamic and first-hand exposure to understand the relationships between four selected cultural elements (i.e. trust, communication between staff, reward, learning \&development), organizational socialization and KT in Bruneian public organizations.

\section{Literature Review}

\subsection{Knowledge Transfer}

In an organizational context, knowledge transfer is a process through which one group (e.g. department or division) is affected by the experience of another group (e.g. department or division) since it involves two or more parties together (Hasan et al., 2013). Transferring knowledge is thought to be an antecedent of organizational learning (Van Grinsven \& Visser, 2011). But most of the authors agree that the transfer of knowledge depends on the individuals' characteristics such as experience, values, motivation, beliefs (Albino, Garavelli, \& Gorgoglione, 2004). Lam and Lambermont-Ford (2010) explained KT as a difficult task since the willingness of individual to share and integrate their knowledge is one of the central barriers for knowledge transfer. Wilkesmann and Wilkesmann (2011) state another important issue that social interaction and processes of personal understanding as well as sense-making are seen to play a more critical role in K. T. Oliver (2001) argued that knowledge could not be transferred intact because learning is an active process of constructing knowledge in the receiver's mind. So the best practice for firms is to develop a KT culture that reinforce the link between KT and business strategy; fit with overall organizational culture; fit with leadership; fit with human and social networks and institutionalization of learning disciplines (Rhodes, Hung, Lok, Lien, \& Wu, 2008). But the bureaucratic organizational cultures tend to mean that employees in the public sector often see knowledge 
management as a management responsibility and not necessarily something for which every employee should take some responsibility (Seba et al., 2012). Therefore, the researchers of this study are not only interested in the KT process, but also in proposing a KT model expedited by trust among public officials, open communication between them, organizational reward system and the learning \& development environment.

\subsection{Organizational Culture}

Organizational culture is thought to be the most important input to effective KT and organizational learning in that corporate culture determines values, beliefs and work systems that could encourage or impede learning (knowledge creation) as well as knowledge sharing, and ultimately, decision making (Janz \& Prasarnphanich, 2003). Schein (1985) defined organizational culture as the, “.... basic assumptions and beliefs that are shared by members of an organization, that operate unconsciously, and that define in a basic taken-for-granted fashion an organization's view of itself and its environment". De Long and Fahey (2000) identify four comprehensive ways in which culture influences: first, culture shapes assumption about what type of knowledge is worth managing; second, culture defines relationships between individual and organizational knowledge, determining who is expected to control specific knowledge, as well as who must share it; third, culture creates the context for social interaction that determines how knowledge will be shared in particular situations; and fourth, culture shapes the processes by which new knowledge with its accompanying uncertainties is created, legitimated and distributed in organizations. Different studies found that cultural elements such as trust, communication, reward system and organizational structure are positively related to knowledge sharing in organizations (Seba et al., 2012; Al-Alawi et al., 2007). Although there are various elements of culture that affect KT, but in this study we focuson four characteristics such as trust, communication between employees, reward and learning \& development. We believe these four cultural elements may influence knowledge transfer in public organizations.

\subsection{Organizational Socialization}

Organizational socialization has been receiving attention in the mainstream management research over the past two decades, particularly in relation to research on learning and knowledge sharing in the organizations (Ostroff \& Kozlowski, 1992; Danielson, 2004). Organizational socialization refers to the process in which a person acquires and shares his or her knowledge, skills and dispositions that make him or her capable member of the organization (Brim \& Wheeler, 1966). Furthermore, Antonacopoulou and Güttel, (2010) also argued in their study about socialization process highlighting how it facilitates the interaction between a stable social system and the new members because it introduces a new employee to the organization with the process of imparting the norms on how to behave in a way that is acceptable to the established social group. Socialization also plays a vital role in the development of employee's affective and behavioral outcomes. Since a new employee joins an organization, his or her immediate task is to understand the setting of the work environment and he/she then comes to terms with its demand. Therefore, the social interaction amongst employees enables the sharing of skills and the establishment of mutual understanding between the members and outsiders. Since knowledge transfer is fundamentally a social process (Rogers, 1995), socialization process can be viewed as an important factor in any type of knowledge transfer as it occurs in a shared social context where different units are linked and interact with one another (Coleman, 1990; Tsai, 2001).

\section{Research Model and Hypothesis Development}

Based on the above literal construct, this study aims to develop a knowledge transfer model involving four key elements of organizational culture (trust, communication between employees, reward and learning \& development); organizational socialization and knowledge transfer. Figure 1 shows the conceptual model of this research:

Every organization depends on a range of key factors e.g. strategy, structure, culture and technology influencing the overall performance of the organization (Galbraith, 2002). It is therefore envisaged that the ability to transfer knowledge effectively in an organization can be enhanced by organizational cultural elements such as trust, communication, reward, and learning \& development. Based on the above conceptual discussions, the study proposes the following four hypotheses:

Trust determines the extent to which an individual is willing to associate and interact with others (Kumar, Rose, \& Muien, 2009). Hock et al. (2009) showcased trust as an important factor after reviewing several studies. Martin (2000) indicates that the key elements of a knowledge culture are a climate of trust and openness in an environment where constant learning and experimentation are highly-valued, appreciated and supported. Kale, Singh \& Perlmutter, (2000) found that trust tends to decrease the perceived risk of opportunism, encouraging members of the expert partner to engage in wide-ranging, continuous and intense contact with members of the novice partner. The level of trust that subsists between the organization, its subunits and its employees 
impressively influences the extent to which employees participate in both open dialogue and the free flow of knowledge; that flows both between individuals and from individuals into the firm's databases, best practices archives, and other records (De Long \& Fahey, 2000).

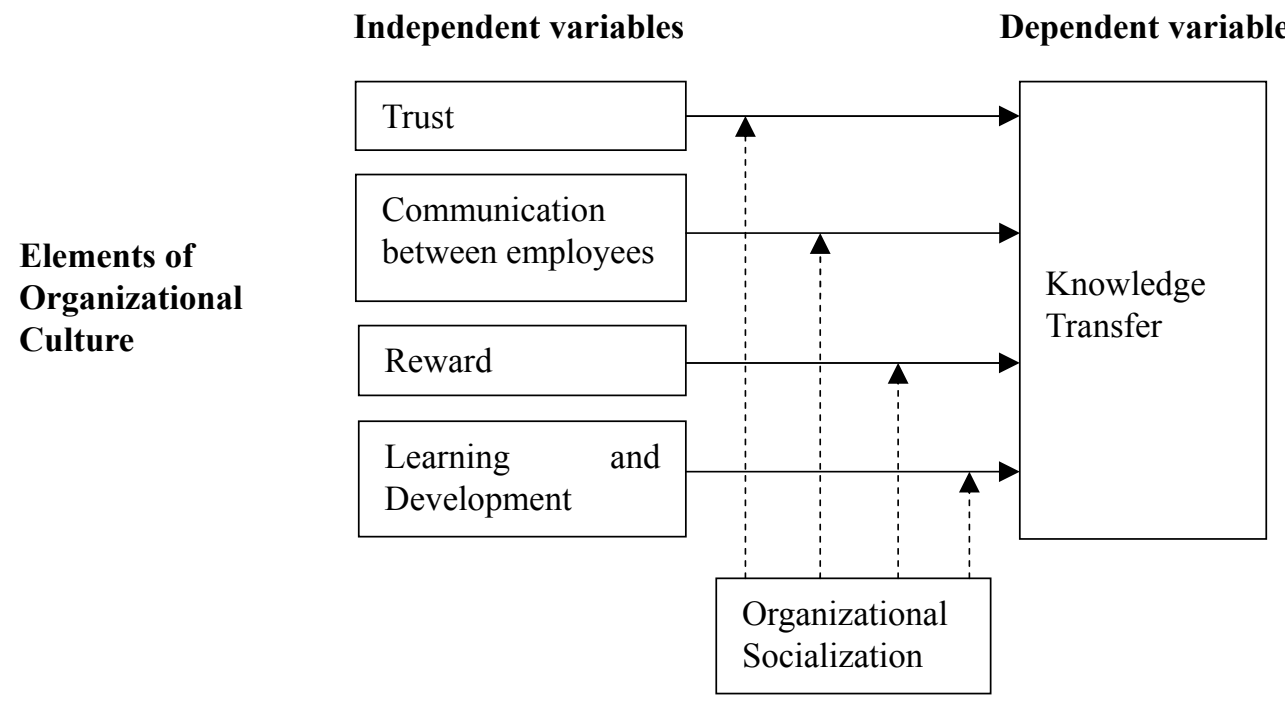

Moderating variable

Figure 1. Research model

H1: Trust has positive relationship with Knowledge Transfer

Communication is a medium between people who are working together to achieve individual or collective organizational goals (Du Plessis \& Boshoff, 2008). Moss and Warnaby (1998) found that communication is required in order to share and transfer knowledge in organizations. Since communication plays a critical role in KT process as for knowledge flow, written, oral or other forms of communication are required, including ICT-supported communication (Du Plessis \& Boshoff, 2008). Complying with these facts Parent et al. (2007) also emphasize that communication facilitates the transfer of knowledge by taking advantage of the team members' connections and history of working together. McEvily et al. (2003) suggest that improvement in KT can be achieved through the openness of communication channels, social networks and trust. Therefore, effective communication process is thought to be a major contributor to the success of change initiatives in organizations.

H2: Communication between employees has positive relationship with Knowledge Transfer

Reward is a measure of how well an organization recognizes employee performance with rewards (Janz \& Prasarnphanich, 2003). Whether incentives are tangible or intangible they are an integral part of the KT process because they can be used to motivate employees to share their knowledge they otherwise may hoard (Hansen et al., 1999). Rewards based on performance are the most appropriate control mechanism for organizations, bearing in mind that knowledge is asymmetrically distributed. But Huber (2001) points out that organizational reward structures such as pay-for-performance compensation schemes could discourage KT if employees believe that knowledge sharing will hinder their personal efforts to distinguish themselves relative to their co-workers. Therefore, providing incentives for donating knowledge in organizations, there is a need to reward employees for using the knowledge available to them.

\section{H3: Reward has positive relationship with Knowledge Transfer}

Organizational learning is described as the way the organizations build, supplement and organize knowledge and routines around their business activities and business cultures, as well as the way they adopt and develop organizational efficiency by improving the use of broad skills of their workforces (Fiol \& Lyles, 1985). A synthesis of the learning literature strongly suggests that learning through knowledge acquisition from relationships (Huber, 1991) allows organizations to gain capabilities and competencies (Teece et al., 1997). Bukowitz and Williams (1999) claimed that the need for a learning strategy that enables KT, which integrates both learning and transfer in the analysis stage is supported by the Knowledge Management Process framework.

H4: Learning and development has positive relationship with Knowledge Transfer 
On the other hand, organizational socialization process also gets importance in knowledge transfer process as it occurs in a shared social context where different units are linked and interact with one another (Coleman, 1990; Tsai, 2001). In addition, the social exchange theory (Blau, 1964) also refers this fact and greater socialization leads to more knowledge transfer. Because the informal and conducive environment within the organization that brings the employee closer to solve problems in organizations more freely and share their views and ideas among themselves lead to organizational knowledge transfer. Thus, we propose:

H5: Organizational socialization moderates the relationship between trust and Knowledge Transfer

H6: Organizational socialization moderates the relationship between communication between employees and Knowledge Transfer

H7: Organizational socialization moderates the relationship between reward and Knowledge Transfer

H8: Organizational socialization the relationship between learning and development and Knowledge Transfer

\section{Methodologies}

The population for this study consists of selected public sector employees in Brunei. The reason why this study has chosen the public officials is that they are important players in decision making and policy implementation as well as the suitable respondents to a research of this nature. A structured questionnaire was used in this study for collecting data from selected respondents from a range of pubic organizations including ministries, departments and a leading public university. The questionnaire consists of four sections having measurement scale for Trust, Communication between employees, Reward, Learning and Development vis-à-vis knowledge transfer. Items of enquiries were adapted from previous studies of similar nature, undertaken by Al-Alawi et al. (2007) and Gold et al. (2001). All questionnaire items were assessed on a five-point Likert-type scale and Cronbach's alpha was used to evaluate the internal consistency of the items, whereas Regression analysis was used to test the hypotheses.

\section{Data Analysis and Results}

Table 1. Demographic characteristics

\begin{tabular}{|c|c|c|c|}
\hline Demographic Variable & Category & Frequency & Percentage \\
\hline \multirow{2}{*}{ Gender } & Male & 67 & 58.8 \\
\hline & Female & 47 & 41.2 \\
\hline \multirow{4}{*}{ Age } & $25-35$ & 8 & 7 \\
\hline & $36-45$ & 45 & 39.5 \\
\hline & $46-50$ & 34 & 29.8 \\
\hline & Above 50 & 27 & 23.7 \\
\hline \multirow{4}{*}{ Education level } & PhD Degree & 9 & 7.9 \\
\hline & Master's Degree & 58 & 50.9 \\
\hline & Bachelor Degree & 45 & 39.5 \\
\hline & Others & 2 & 1.8 \\
\hline \multirow{4}{*}{ Your Position in the organization } & Top level manager & 24 & 21.1 \\
\hline & Middle level manager & 58 & 50.9 \\
\hline & Lower level manager & 25 & 21.9 \\
\hline & Others & 7 & 6.1 \\
\hline \multirow{6}{*}{ Number of Employees in your organization } & Less than 100 & 33 & 28.9 \\
\hline & $100-200$ & 28 & 24.6 \\
\hline & $201-300$ & 14 & 12.3 \\
\hline & $301-400$ & 12 & 10.5 \\
\hline & $401-500$ & 7 & 6.1 \\
\hline & above 500 & 18 & 15.8 \\
\hline \multirow{5}{*}{$\begin{array}{l}\text { How long have you been working in your } \\
\text { current organization }\end{array}$} & Less than 2 years & 22 & 19.3 \\
\hline & $2-4$ years & 10 & 8.8 \\
\hline & 5-7 years & 12 & 10.5 \\
\hline & $8-10$ years & 14 & 12.3 \\
\hline & More than 10 years & 56 & 49.1 \\
\hline
\end{tabular}


A total of 120 questionnaires were distributed, 114 were received with a $95 \%$ response rate. From among the respondents, about $49.1 \%$ government officers have been working in public service for over 10 years. Around, $21.1 \%$ of the respondents are holding top management positions, $50.9 \%$ are middle level managers, 25 are junior managers (21.9 percent) and the remainder included other circles of 6.1 percent. The number of employees in the study organizations varies: $28.9 \%$ of the organizations have less than 100 employees, $24.6 \%$ have between 100 and $200,12.3 \%$ are staffed with $201-300,10.5 \%$ have between 301 and $400,6.1 \%$ between 401 to 500 and $15.8 \%$ organizations have a top strength of over 500 people. It shows that all sizes of public organizations (i.e. large-medium-small) were represented in the survey. In terms of educational attainment and age, there is a typical mix of backgrounds. In terms of education for example, only a few (7.9\%) have the top PhD qualification, and others are almost equally divided between Master's (50.9 \%) and Bachelor's degree (39.5\%). Table 1 details the other demographic characteristics including gender, age, and length of service.

Table 2 illustrates the reliability assessments for independent variables and dependent variable to describe the internal consistency and stability of data. The reliability analysis confirms the degree to which items in each set correlate with one another. Cronbach's Alpha was used in this study to establish this inter-item consistency.

Table 2. Summary of reliability analysis

\begin{tabular}{lcc}
\hline Variables & Number of items & Cronbach's $\alpha$ \\
\hline Trust & 6 & 0.72 \\
Communication between employees & 3 & 0.80 \\
Reward & 3 & 0.82 \\
Learning and Development & 6 & 0.82 \\
Organizational Socialization & 6 & 0.89 \\
Knowledge Transfer & 5 & 0.82 \\
\hline
\end{tabular}

\subsection{Hypotheses Testing}

Table 3. Regression summery

\begin{tabular}{lll}
\hline Variable & $\beta$ & Sig. \\
\hline Trust & 009 & .925 \\
Communication between employees & .124 & .161 \\
Reward & .141 & .129 \\
Learning and Development & .495 & .000 \\
$\mathrm{R}^{2}=0.417$ & & \\
Sig. $=0.000$ & & \\
Durbin Watson $=1.862$ & & \\
F-value $=19.467$ & & \\
\hline
\end{tabular}

Regression analysis was used to test the relationship between the dimensions of organizational culture and KT. A significant level of 0.05 or $5 \%$ significance is considered as a basic for accepting or rejecting the hypotheses. Regression analysis was conducted to test Hypotheses 1 to 4 . In table 3, the coefficient of $\mathrm{R}^{2}$ is 0.417 indicating that the independent variables of organizational culture elements can explain $41.7 \%$ of the variance of KT. Durbin Watson of 1.862 indicates that there is no auto-correlation problem. Tolerance and VIF values are also in the acceptable range, which indicate there are no multi-collinearity problems.

Table 4 illustrates the results of the hierarchical regression when moderating the variable organizational socialization was granted as a moderating variable. The coefficient determination of $\mathrm{R}^{2}$ significantly increases to 0.55 when organizational socialization is considered as a moderating variable.

From the hierarchical regression, it was found that the moderator organizational socialization was significant enough to be considered as an independent variable; however, as proposed in the study, the model plays a role as a moderator. The hypothesized relationship between trust and knowledge transfer which was rejected in model 1 is positively moderated by Orgs in model 3 . 
Therefore, from the findings above, we can accept the following hypotheses:

H4: Learning and development has positive relationship with Knowledge Transfer;

H5: organizational socialization moderates the relationship between trust and Knowledge Transfer.

Table 4. Hierarchical regression summery

\begin{tabular}{|c|c|c|c|c|c|c|c|}
\hline & $\beta$ & Sig. & $\mathrm{R}^{2}$ & $\begin{array}{c}\mathrm{R}^{2} \\
\text { Change }\end{array}$ & $\begin{array}{c}\mathrm{F} \\
\text { Change }\end{array}$ & $\begin{array}{l}\text { Sig. F } \\
\text { Change }\end{array}$ & $\begin{array}{l}\text { Durbin } \\
\text { Watson }\end{array}$ \\
\hline \multicolumn{8}{|l|}{ Variables } \\
\hline Trust (Tru) & -0.07 & 0.46 & & & & & \\
\hline $\begin{array}{l}\text { Communication between employees } \\
\text { (Com) }\end{array}$ & -0.02 & 0.85 & & & & & \\
\hline Reward (Rew) & 0.07 & 0.41 & & & & & \\
\hline Learning and Development (Lear) & 0.30 & 0.02 & & & & & \\
\hline Organizational Socialization (Orgs) & 0.45 & 0.00 & & & & & \\
\hline $\operatorname{Tru} \times$ Orgs & 1.66 & 0.04 & & & & & \\
\hline Com $\times$ Orgs & 0.33 & 0.62 & & & & & \\
\hline Rew $\times$ Orgs & -0.93 & 0.15 & & & & & \\
\hline Lear $\times$ Orgs & -0.63 & 0.35 & & & & & \\
\hline \multicolumn{8}{|l|}{ Model } \\
\hline 1 & & & 0.42 & 0.42 & 19.47 & 0.00 & \\
\hline 2 & & & 0.49 & 0.08 & 16.25 & 0.00 & \\
\hline 3 & & & 0.55 & 0.06 & 3.54 & 0.09 & 1.8 \\
\hline
\end{tabular}

\section{Research Findings}

This study examined the relationships between cultural elements (trust, communication between staff, reward and learning \& development) and KT. The findings concluded that trust has insignificant relationship with KT; in fact this dimension of organizational culture is negatively related with KT process in the public sector organizations in Brunei. This result contradict with the research findings of Migdadi (2009) and Seba et al. (2012) which found trust as one of the most commonly stated factors to affect knowledge creation and transfer around the world. Heumer et al. (1998) argue that trust facilitates learning between partners, and that decisions to exchange knowledge under certain conditions are based on trust. This surprising outcome in the public organizations in Brunei indicates that when there are cognitive codes of trust, employees are not only willing to listen to others but are also able to absorb knowledge from others (Seba et al., 2012).

Communication between employees shows insignificant relationship with KT and the results of this correlation fully disagree with the studies by Al-Alawi et al. (2007) and Parent et al. (2007). Since communication between employees is one of the important aspects for KT, this study shows different outcome which confirms that public organizations operating in Brunei have lack of focus on internal communication. Therefore, it would be good for public organizations to maintain a proper communication system where employees could communicate with each other frequently in the direction of solving problems related with the successful transfer of knowledge.

Reward is also found to have insignificant relationship with KT. Again, the findings of this study are different from the findings of Migdadi (2009). Hansen et al. (1999) found in their study that whether incentives are tangible or intangible they are an integral part of the KT process because they can be used to motivate employees to share their knowledge they otherwise may hoard. This actually complies with the findings of this study that reward system may not be working up to its expected level in the public sector organizations of Brunei. Oliver and Kandadi (2006) claim that respondents of their study suggested that indirect reward such as appreciation and recognition played a big role than the monetary incentives. Therefore, in offering incentives for participation in the KT public organizations in Brunei need to deliver the appropriate incentives.

It is the fourth element-learning \& development-that shows positive and significant relationship with KT. This result fully complies with the study of Migdadi (2009) and Rhodes et al. (2008). Rhodes et al. (2008) suggested that knowledge management could be viewed as a social process and KT as part of organizational learning since 
a major objective in KT is the organizational accessibility of this knowledge. Learning as the ability to learn from others and the culture of openness within the organization could have significant impact on how knowledge is transferred. Considering this finding it can be claimed that the Bruneian public sector entities are believed to be enhancing KT through learning and development.

The relationship between trust and knowledge transfer is positively moderated by organizational socialization. Organizational socialization makes the way easy for the employees to acquire and sharetheir knowledge, skills and dispositions through a stable social system where members are going to be familiarized with the existing system which may play an important role in the employee's behavioral outcomes (Antonacopoulou \& Güttel, 2010). Consequently, knowledge transfer is considered as a social process because transferring knowledge between employees in different units in the organization can be possible by linking and interacting employees with one another (Coleman, 1990; Tsai, 2001). Therefore, practicing this process will increase the trustworthiness among employees towards an effective knowledge transfer.

\section{Implications of the Study}

The contribution of this research can be seen in the following ways:

a) There is limited research on knowledge transfer in the public sector organizations in Brunei. This empirical research contributes on the future theoretical knowledge on the subject.

b) This is one of the few studies in Brunei that examines the views of cultural aspects that effects knowledge transferring behavior among the employees in public organizations in the sultanate.

c) The study also reveals why knowledge transferring behavior is not sustained as a whole considering the negative correlation between KT and trust, communication, and reward aspects. This may need a potential explanation by another level of research to identify the issues and to suggest how these three elements of organizational culture could ease knowledge transfer rather than obstruct it.

d) The study also encourages the socialization process in to the organizations as it increases the interaction between employees through trust which is one of the predetermined factors in knowledge management literature for successful knowledge transfer. Therefore, emphasizing more socialization may react differently in future studies by confirming other variables as a significant predictor of KT.

However, in this study we examined a theoretical model, hypothesizing the relationship between four organizational culture elements and KT with a moderator organizational socialization. Based on the results of the study some practical implications can be drawn for the public sector organizations in Brunei. Since knowledge management is recognized as a source of competitive advantage for organizations, learning about other factors that may facilitate a rapid and successful transfer of knowledge within organizational units is imperative. Therefore public organizations should set priorities in allocating resources to optimize the opportunities for better KT and organizational performance. On the other hand, results of this study and more in-depth studies in the future will help the policymakers in Brunei to configure a system or policy towards sustainable knowledge transfer in the public organizations that can improve service excellence and in the long run lead to achieving the national strategic vision of 2035. Moreover, the proposed model of this study can also be tested in different organizational setup of other countries to draw a general conclusion.

\section{Suggestions for Future Research}

The study uncovered a number of opportunities to further examine the reasons for less correlation between the three above cultural elements and knowledge transfer in order to address any inadequacies in the current public sector organizational environment in Brunei. After what has been an exploratory research, a diagnostic and analytical study will now help identify the real issues behind the disconnect between knowledge transfer and the three studied elements. Few other elements including leadership and organizational structure could also be looked into to see how they influence the knowledge behavior among the public officials in Brunei. A next step in research could also include private sector to see how different is their cultural environment and elements in terms of influencing knowledge transfer.

\section{Conclusions}

The study has revealed different literal constructs to see the importance of knowledge transfer in public organizations in a given context of Brunei as knowledge is considered one of the key resources to improve organizational value and performance. Though learning and development are found to be the only significantly important catalyst for knowledge transfer in the Bruneian public bodies, only learning and development could not be able to motivate the flow of knowledge sharing in organizations. Therefore, the socialization practice 
should be prioritized in the premise of Bruneian public organizations for an improved outcome of knowledge transfer.

The study is limited by some reasons: first, the sample size of this study is too small which has been modestly targeted due to time and resource constrains; second, the convenience sampling limits generalization of results; third, the difficulty of getting response also limits the study and finally, the study did not cover all types of public sector organizations in Brunei. Nonetheless, this technique has been often used by knowledge management research (Islam et al., 2011). In conclusion, we suggest future research opportunities to be taken to examine the others factors in the public sector and private sector organizations in Brunei.

\section{References}

Al-Alawi, I. A., Al-Marzooqi, Y. N., \& Mohammed, F. Y. (2007). Organizational culture and knowledge sharing: Critical success factors. Journal of Knowledge Management, 11(2), 22-42. http://dx.doi.org/10.1108/13673 270710738898

Albino, V., Garavelli, A. C., \& Gorgoglione, M. (2004). Organization and technology in knowledge transfer. Benchmarking: An International Journal, 11(6), 584-600. http://dx.doi.org/10.1108/14635770410566492

Antonacopoulou, E. P., \& Güttel, W. H. (2010). Staff induction practices and organizational socialization. Society and Business Review, 5(1), 22-47. http://dx.doi.org/10.1108/17465681011017246

Blau, P. (1964). Exchange and power in social life. New York: Wiley.

Bovaird, T., \& Loffler, E. (2009). Public Management and Governance. Routledge, London.

Brim, O. G., \& Wheeler, S. (1966). Socialization after childhood: Two essays. New York: John Wiley \& Sons.

Bukowitz, W., \& Williams, R. (1999). The Knowledge Management Field book. Financial Times Prentice Hall, London.

Bulletin, B. (2014). Sutan's New Year 2014 Titah (Speech). Retrieved January 2, 2014, from http://www.bruneigamers.com/sultans-new-year-2014-titah/\#sthash.CMEOmT2A.dpbs

Choi, S. Y., Kang, Y. S., \& Lee, H. (2008). The effects of socio-technical enablers on knowledge sharing: An exploratory examination. Journal of Information Science, 34(5), 742-754. http://dx.doi.org/10.1177/0165 551507087710

Coleman, D. (1990). Groupware: Collaboration and knowledge sharing. In J. Liebowitz (Ed.), Knowledge Management hand book. Florida: CRC press.

Conner, K. R., \& Prahalad, C. K. (1996). A resource-based theory of the firm: Knowledge versus Opportunism. Organizational Science, 7(5), 477-501. http://dx.doi.org/10.1287/orsc.7.5.477

Danielson, M. M. (2004). A theory of continuous socialization for organizational renewal. Human Resource Development Review, 3(4), 354-384. http://dx.doi.org/10.1177/1534484304271528

Davenport, T. H., De Long, D. W., \& Beers, M. C. (1998). Successful knowledge management projects. Sloan Management Review, 39(2), 43-57.

De Long, D. W., \& Fahey, L. (2000). Diagnosing cultural barriers to knowledge management. Academy of Management Executive, 14(4), 113-127.

Du Plessis, T., \& Boshoffm, M. (2008). Preferred communication methods and technologies for organizational knowledge sharing and decision making. South African Journal of Information Management, 10(2), 1-18.

Farhana, T. (2013). Performance management in the Brunei public sector. Proceedings of European Business Research Conference. Sheraton Roma, Rome, Italy, 5-6 September 2013.

Fiol, C. M., \& Lyles, M. A. (1985). Organizational learning. Academy of Management Review, 10(4), 803-813.

Galbraith, J. (2002). Designing Organizations: An Executive Guide to Strategy, Structure, and Process Revised. Jossey Bass, San Francisco, CA.

Gold, A. H., Malhotra, A., \& Albert, H. S. (2001). Knowledge Management: An Organizational Capabilities Perspective. Journal of Management Information systems, 18(1), 185-214.

Government of Brunei. (2014). Economic Development Board. Brunei's National Vision. Retrieved from http://www.bedb.com.bn/why_wawasan2035.html

Grant, R. M. (1996). Prospering in dynamically competitive environments: Organizational capability as knowledge integration. Organization Science, 7(4), 109-122. http://dx.doi.org/10.1287/orsc.7.4.375 
Handzic, M. (2011). Integrated socio-technical knowledge management model: An empirical evaluation. Journal of Knowledge Management, 15(2), 198-211. http://dx.doi.org/10.1108/13673271111119655

Hansen, M., Nohira, N., \& Tierney, T. (1999). What's your strategy for managing knowledge? Harvard Business Review, 77(2), 106-117.

Hasan, I., Low, P. K. C., \& Islam, M. Z. (2013). Knowledge management, Knowledge Transfer and Corporate Social Responsibility (CSR). Springer link: Encyclopedia of Corporate Social Responsibility, 1555-1562.

Heumer, L., Krogh, G., \& Roos, J. (1998). Knowledge and the concept of trust. In G. Krogh, J. Roos, \& D. Klein (Eds.), Knowing in Firms. Sage Publications Ltd., London.

Hock, N. T., Ling, T. N., \& San, L.Y. (2009). Trust: facilitator of knowledge-sharing culture. Communications of the IBIMA, 7(15), 137-142.

Huber, G. P. (1991). Organizational learning: The contributing processes and the literatures. Organization Science, 2(1), 88-115. http://dx.doi.org/10.1287/orsc.2.1.88

Huber, G. P. (2001). Transfer of knowledge in knowledge management systems: Unexplored issues and suggested studies. European Journal of Information Systems, 10(2), 72-79. http://dx.doi.org/10.1057/ palgrave.ejis.3000399

Islam, M. Z., Ahmed, S. M., Hasan, I., \& Ahmed, S. U. (2011). Organizational Culture and Knowledge Sharing: Empirical Evidence from the Service Organization. African Journal of Business Management, 5(14), 5900-5909.

Ives, W., Torrey, B., \& Gordon, C. (2003). Knowledge transfer: Transfer is human behavior. In C. Morey, M. Maybury, \& B. Thuraisingham (Eds.), Knowledge Management: Classic and Contemporary Works. MIT Press, Cambridge, MA.

Janz, B. D., \& Prasarnphanich, P. (2003). Understanding the antecedents of effective knowledge management: The importance of a knowledge-centered culture. Decision Sciences, 34(2), 351-384. http://dx.doi.org/10. $1111 / 1540-5915.02328$

Jasimuddin, S. M. (2012). Knowledge management: An interdisciplinary perspective. New Jersey, NY: World Scientific Publishing Co Pte Ltd. http://dx.doi.org/10.1142/7246

Kale, P., Singh, H., \& Perlmutter, H. (2000). Learning and protection of proprietary assets in strategic alliances: Building relational capital. Strategic Management Journal, 21(3), 217-237. http://dx.doi.org/10.1002/(SICI) 1097-0266(200003)21:3<217::AID-SMJ95>3.0.CO;2-Y

Kumar, N., Rose, R. C., \& Muien, N. F. A. (2009). The influences of absorptive capacity and social capital on knowledge transfer. The Journal of Applied Business Research, 25(4), 99.

Kusunoki, K. I., Nonaka, I., \& Nagata, A. (1998). Organisational capabilities in product development of Japanese firms: A conceptual framework and empirical findings. Organization Science, 9, 699-718. http://dx.doi.org/10.1287/orsc.9.6.699

Lam, A., \& Lambermont-Ford, J. P. (2010). Knowledge sharing in organisational contexts: A motivation-based perspective. Journal of Knowledge Management, 14(1), 51-66. http://dx.doi.org/10.1108/1367327 1011015561

Martin, B. (2000). Knowledge management within the context of management: An evolving relationship. Singapore Management Review, 22(2), 17.

McEvily, B., Perrone, V., \& Zaheer, A. (2003). Trust as an organizing principle. Organization Science, 14(1), 91-103. http://dx.doi.org/10.1287/orsc.14.1.91.12814

Migdadi, M. M. (2009). A knowledge-centered culture as an antecedent of effective knowledge management at information technology centers in the Jordanian universities. Journal of Systems and Information Technology, 11(2), 89-116. http://dx.doi.org/10.1108/13287260910955084

Moss, D., \& Warnaby, G. (1998). Communications strategy? Strategy communication? Integrating different perspectives. Journal of Marketing Communications, 4(3), 131-140. http://dx.doi.org/10.1080/13527269 8345807

Noorazah, M. N., \& Salim, J. (2011). Factors influencing employee knowledge sharing capabilities in electronic government agencies in Malaysia. International Journal of Computer Science Issues, 8(4), 106.

Oliver, R. (2001). Developing e-learning environments that support knowledge construction in higher education. 
In S. Stoney, \& J. Burn (Eds.), Working for Excellence in the E-economy (pp. 407-416). We-B Centre, Churchlands.

Oliver, S., \& Kandadi, K. D. (2006). How to develop knowledge culture in organizations? A multiple case study of large distributed organizations. Journal of Knowledge Management, 10(4), 6-24. http://dx.doi.org/10.11 $08 / 13673270610679336$

Ostroff, C., \& Kozlowski, S. W. J. (1992). Organizational socialization as a learning process: The role of information acquisition. Personnel Psychology, 45(4), 849-874. http://dx.doi.org/10.1111/j.1744-6570.1992. tb00971.x

Parent, R., Roy, M., \& St-Jacques, D. (2007). A system-based dynamic knowledge transfer model. Journal of Knowledge Management, 11(6), 81-93. http://dx.doi.org/10.1108/13673270710832181

Rhodes, J., Hung, R., Lok, P., Lien, B. Y. H., \& Wu, C. M. (2008). Factors influencing organizational KT: Implication for corporate performance. Journal of Knowledge Management, 12(3), 84-100. http://dx.doi.org $/ 10.1108 / 13673270810875886$

Rogers, E. M. (1995). Diffusion of innovations. New York: Free Press.

Schein, E. H. (1985). Organizational Culture and Leadership: A Dynamic View. Jossey-Bass

Seba, I., Rowley, J., \& Delbridge, R. (2012). Knowledge sharing in the Dubai Police Force. Journal of Knowledge Management, 16(1), 114-128. http://dx.doi.org/10.1108/13673271211198972

Teece, D. J., Pisano, G., \& Shuen, A. (1997). Dynamic capabilities and strategic management. Strategic Management Journal, 18, 509-533. http://dx.doi.org/10.1002/(SICI)1097-0266(199708)18:7<509::AID-SM $\mathrm{J} 882>3.0 . \mathrm{CO} ; 2-\mathrm{Z}$

Tsai, W. (2001). Knowledge transfer in intra organizational networks: Effect of network position and absorptive capacity on business unit innovation and performance. Academy of Management Journal, 44(5), 45-61. http://dx.doi.org/10.2307/3069443

Van Grinsven, M., \& Visser, M. (2011). Empowerment, knowledge conversion and dimensions of organizational learning. Learning Organization, 18(5), 392-405. http://dx.doi.org/10.1108/09696471111151729

Wilkesmann, M., \& Wilkesmann, U. (2011). Knowledge transfer as interaction between experts and novices supported by technology. VINE, 41(2), 96-112. http://dx.doi.org/10.1108/03055721111134763

Zhang, P., \& Ng, F. F. (2012). Attitude toward knowledge sharing in construction teams. Industrial Management \& Data Systems, 112(9), 1326-1347. http://dx.doi.org/10.1108/02635571211278956

\section{Copyrights}

Copyright for this article is retained by the author(s), with first publication rights granted to the journal.

This is an open-access article distributed under the terms and conditions of the Creative Commons Attribution license (http://creativecommons.org/licenses/by/3.0/). 